\title{
Zero-Liquid Discharge Desalination of Hypersaline Shale Gas Wastewater: Challenges and Future Directions
}

\section{Introduction}

Unconventional natural gas extraction from tight shale reservoirs, or "shale gas", has recently emerged as an attractive energy resource to face the rising worldwide demand. Over the past decade, advanced technologies of horizontal drilling and hydraulic fracturing ("fracking") have allowed the economic viability of shale gas exploration from previously unattainable deposits. Despite optimistic growth projections from the U.S. Energy Information Administration [1,2], shale gas production is also responsible for worrying environmental and social implications, which are related, among others, to elevated freshwater consumption and hazardous wastewater generation [3]. Within this framework, the application of effective desalination processes is mandatory to treat the large amounts of polluting hypersaline wastewater, alleviating environmental and public health impacts and enhancing overall sustainability of shale gas process $[4,5]$. Hence, the ability of zero-liquid discharge (ZLD) desalination to promote water reuse and/or water recycling (i.e., water reuse opportunities aside from shale gas operations) could be critical for further development of the shale gas industry. This work outlines the main challenges and future directions for the wide implementation of ZID desalination processes for shale gas wastewater.

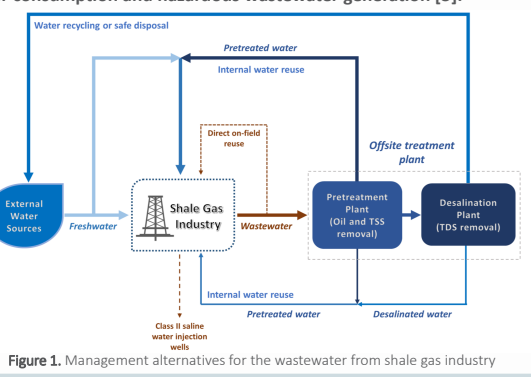

\section{ZLD Desalination for Wastewater Management: Emerging Zero-Emission Technologies}

ZLD desalination, as a strategy for shale gas wastewater management, has received increased interest in the past few years. This is mainly due to its capability to comply with the severe regulations on water quality-especially for allowing water recycling or safe disposal-by enhancing freshwater recovery efficiency, while reducing brine discharges [6]. Emerging technologies for the ZLD desalination of shale gas wastewater comprise thermal and membrane-based processes. Thermal-based desalination alternatives include multistage flash distillation (MSF), and single/multiple-effect evaporation systems combined with mechanical/thermal vapor compression (SEE/MEEMVC/TVC) [7]. On the other hand, membrane distillation (MD), forward osmosis (FO), reverse osmosis (RO), and electrodialysis (ED), are promising membrane-based processes. Evidently, the selection of the most appropriate desalination alternative is greatly dependent on the wastewater physicochemical composition [8].

Apart from the possibility to be operated with low-grade energy sources, membrane-based schemes generally present high water recovery efficiencies, simple scale-up and modular features, and elevated permeability and selectivity for critical components [9]. However, thermal evaporation systems can be more advantageous than membrane ones for the zero-emission treatment of shale gas wastewater, as a result of their need for less intensive pretreatment and lower susceptibility to fouling and rusting problems that can be caused by the presence of greases, oil and scale-forming ions [10]
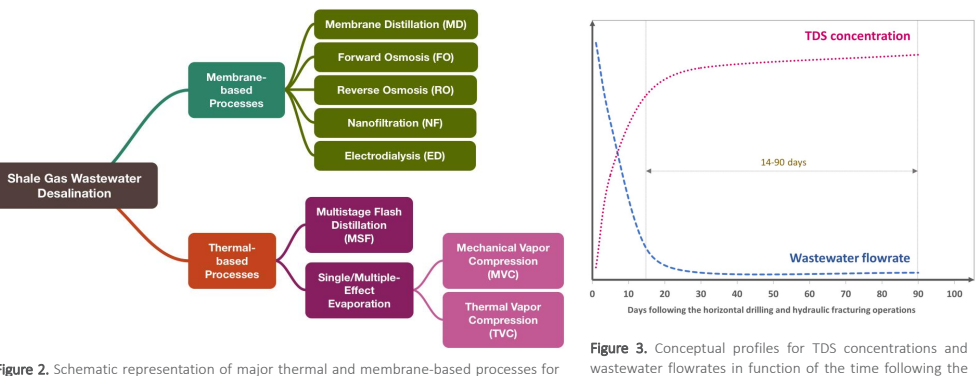

Figure 2 sction

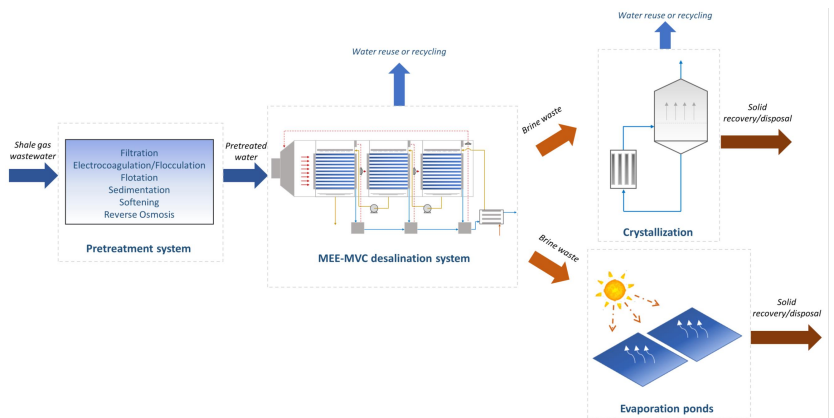

\section{Challenges of ZLD Desalination of Hypersaline Shale Gas Wastewater}

Shale gas wastewater generated by hydraulically-fractured wells can present chemical and physical properties varying according to different factors, which include geographic location and formation geology, hydrofracturing fluid composition, as well as its time of contact with shale deposits $[8,10]$. Also, the concentration of chemicals in shale gas wastewater may change over the time of well exploration [10]. In addition to the chemical additives used within fracking fluids, shale gas wastewater generally contains formation-hased_constituents, comprising salt and other mineralssuch as the scale-forming divalent ions: $\mathrm{Ca}, \mathrm{Ba}$ and $\mathrm{Mg}-$, organic matter and naturally occurring radioactive materials (NORM) [11,12].

Among them, removal of the elevated salt contents from shale gas wastewater (average values $>100 \mathrm{k}$ ppm TDS - Total Dissolved Solids) is notably challenging because of the energy-intensive consumption required to achieve the ZLD brine conditions. In Onishi et al. [5], thermal technologies for ZLD desalination (brine sdischarge at $300 \mathrm{~g} \mathrm{~kg}$ ) have presented energy consumption in a sange of 28.12-50.47 kWh m , with specific operational costs estimated between 2.73-4.90 us\$ $\mathrm{m}$ for $77 \%$ conversion ratio. Furthermore, another complicating factor is related to the significant composition variations observed in wastewater from different shale basins, and even in distinct wellbores from the same well pad [13].

The elevated consumption of high-grade electrical energy is also responsible for significant greenhouse gas (GHG) emissions. Besides the prohibitive costs related to the raised energy consumption, high salt concentrations in the shale gas wastewater pose particular desalination challenges, mostly associated with operational problems caused by fouling, scaling and corrosion [14]. Due to changes in process temperature conditions, fouling and scaling can reduce heat transfer in thermal systems and mass transfer rate in membrane-based technologies. Lastly, appropriate management of the generated solid brine should be considered to avoid potential environmental impacts.

\section{Outlook and Future Directions}

The main advantages of ZLD systems include their ability to achieve high water efficiencies and comply with tight water quality regulations, allowing almost the totally of water contents in wastewater to be reclaimed for reuse or even recycling opportunities.

Despite of the increasing worldwide interest on the implementation of ZLD desalination systems, their intensive energy consumption and high related operating costs remain as obstacles for their further adoption. Future advances on ZLD applications will ultimately be achieved by the development of more energy efficient and sustainable thermalbased desalination processes. Also, technological advances in fouling control, membranes materials and draw solutions, together with operating conditions optimization, should further increase economic and energy efficiency affordability of membrane ZLD desalination systems within shale gas activity.

Eventually, stricter regulations on wastewater disposal and water quality, along with the raise in wastewater disposal costs and regulatory incentives for financial counterweighting, should drive shale gas industry towards the adoption of cleaner ZLD desalination systems.

\section{References}

[1] EAA. Annual Energy Outlook 2016 with Projections to 2040. Washington, DC: U.S. Energy Information Administration, 2016.

[3] Thomas $\mathrm{M}$, Partridge $\mathrm{T}$, Harthorn $\mathrm{BH}$, Pidgeon $\mathrm{N}$. Deliberating the perceived risks, benefits, and societal implications of shale gas and
oil extraction by hydraulic fracturing in the US and UK. Nat Energy 2017:2: 17054 . [4] Onishi VC, Carrero-Parreño A, Reyes-Labarta JA, Fraga ES, Caballero JA. Desalination of shale gas produced water: A rigorous design [5] Onishi VC, Carrero-Parreño A, Reyes-Labarta JA, Ruiz-femenia R, Salcedo-Díaz R, Fraga ES, et al. Shale gas flowback water desalination [6] Tong T, Elimelech M. The Global R
Environ Sci Technol 2016;50:6846-55.

[7] Onishi VC, Ruiz-Femenia R, Salcedo-Diaz R, Carrero-Parreño A, Reyes-Labarta JA, Fraga ES, et al. Process optimization for zero-liquid

[8] Lester Y, Ferrer I, Thurman EM, Sitterley KA, Korak JA, Aiken G, et al. Characterization of hydraulic fracturing flowback water in Colorado [9] Drioli E, Ali A, Lee YM, Al-Sharif SF, Al-Beirutty M, Macedonio F. Membrane operations for produced water treatment. Desalin Water
Treat 2016;57:14317-35. [110] Shaffer DL, Arias Chavez LH, Ben-Sasson M, Romero-Varras Castrillón S, Yip NY, Elimelech M. Desalination and Reuse of High-Salinity
Shale Gas Produced Water: Drivers, Technologies, and future Directions. Evviron Sci Technol 2013;47:9569-83. [11] Zhang T, Gregory K, Hammack RW, Vidic RD. Co-precipitation of Radium with Barium and Strontium Sulfate and Its Impact on the Fate of
Radium during Treatment of Produced Water from Unconventional Gas Extraction. Environ Sci Technol 2014;48: $4596-603$.

[12] Rahm BG, Riha S.
Policy 2012;17:12-23.

[113] Thiel GP, Lienhard JH. Treating produced water from hydraulic fracturing: Composition effects on scale formation and desalination
system selection. Desalination 2014;346:54-69. [14] Kaplan R, Mamrosh D, Salih HH, Dastgheib SA. Asses
potential CO2 storage site. Desalination 2017;404:87-101.

\section{Acknowledgement}

This project has received funding from the Europe
programme under grant agreement No. 640979 